\title{
Clustering Ambiguities: How Companies and Public Bodies Develop a Cluster
}

\author{
https://doi.org/10.3991/ijac.v12i1.9741 \\ Gunnar Andersson $(\bowtie)$ \\ Østfold University College, Norway \\ gunnar.andersson@hiof . no \\ Frode Ramstad Johansen \\ Østfold University College Norway and Aalborg University Denmark \\ Synnøve Rubach \\ Østfold research, Norway
}

\begin{abstract}
This study explores the way in which companies and public bodies reflect and argue regarding their own engagement in a cluster project. The aim is to create a focus on clustering and to contribute to the understanding of how cluster involvement affects an organisation. Action net models are employed, unfolding engagement as it is revealed in interviews with representatives of participating private companies and public bodies. The outcome identifies a decoupling in the cluster project producing two clearly divided communities of actors. One comprises public bodies and the facilitating organisation, and one, private companies and R\&D projects. A small group of actors harmonise transactions between the two communities. The decoupling of the cluster is described differently with regard to relating to, engaging in and understanding the cluster project. Discussions replace dependency with agency as the mechanism applied in clustering, illustrating that the cluster project is a meeting place of temporary and competing mindsets and practices. Clustering is portrayed as an ambiguous venture continuously challenging and confronting its own engagement and rationality.
\end{abstract}

Keywords- Clustering, action net, agency

\section{$1 \quad$ Introduction}

This study explores a cluster project as part of a government-supported innovation clusters program. The program is based on an understanding of a cluster as a "geographical concentration of enterprises and related knowledge communities linked by complementarity or a similarity of interests and needs." The cluster project is a time limited attempt to strengthen the development of the cluster.

Clusters are generally understood to contribute to increased competitiveness and productivity, encouraging diffusion of knowledge and best practices within a region. 
The cluster rationale has been adopted by governance and public bodies and has become a major tool in the support of increased competitiveness and productivity within regions. Clustering is treated as a process that is bound by history [1, p. 19] and understood as a path dependent phenomenon where structure is both medium and outcome [2, p. 760]. Miles, Miles, \& Snow [3, p. 85] dispute whether this understanding encloses "a network of independent firms engaging in collaborative entrepreneurship." It captures neither the role of agency [4] nor explains "how and why clusters can take multiple development paths" [5, p. 2033]. It overemphasises structures [6] and too little attention is given to the applied mechanisms to explain how clusters contribute to increased competitiveness in companies [7] and how one can manoeuvre within this kind of cooperative initiatives [8].

- Karnøe \& Garud [9] argue that it fails to account for the dynamics at the micro level in the process, and misses out "the agencies involved in bringing about new clusters in industrial regions". The vital role of entrepreneurs in the cluster creation process is one example illustrating the importance of human agency.

- Trippl et al [5] argue that the recent cluster life-cycle literature does not fully explain how clusters can take multiple development paths. They identify several missing elements including the importance of 'place specificity', multiscale perspective and 'the role of human agency' [5, p. 2028].

- Martin \& Sunley [6] pose the question as to whether the existing cluster rationale does in fact need a theory of human agency. "In what ways is path dependence intentionally created by actors, and in what ways an unintentional emergent effect at system level?" [6, p. 404].

- Andersson [7] argues that the place-based explanations are not reliable, because they fail to account for mechanisms that explain how clusters contribute to increased competitiveness and productivity in a satisfactory manner.

- Rubach [8] identifies the challenges involved in influencing internal company development processes, and thereby also the company's existing resources and networks. She argues that too little attention is given to manoeuvering within this type of cooperative initiative.

The analytical and normative shortcomings and the added complexity and challenges introduced into a cluster with regard to structure and relationships renew and actualise the way in which organisations reflect on their own actions and learn from events.

"After a major event--a product failure, a downsizing crisis, or a merger--many companies stumble along, oblivious to the lessons of the past. Mistakes get repeated, but smart decisions do not. Most important, the old ways of thinking that led to the mistakes are never discussed, which often means that they are still in place to spawn new mishaps again and again.” [10, p. 172]

Kleiner \& Roth's argument is difficult enough when applied to a company, but might be even more challenging in a cluster project because the network of actors, structures and activities are both weaker and more complex than within a company [11], [12]. 
Paper-Clustering Ambiguities: How Companies and Public Bodies Develop a Cluster

Cluster engagement may be seen as "unusual experiences" challenging the old ways of thinking [13].

This study explores the way in which companies and public bodies reflect and argue regarding their own engagement in a cluster, bringing clustering into focus, contributing to the understanding of how cluster involvement affects an organisation.

\subsection{Position}

The problem statement challenges the path dependent literature and the notion that clustering is bound by history. It challenges both the core idea of dependency and its intended function.

Path dependence suggests that "temporally remote" events play a key role in the development of novelty and that these events only gain significance post hoc. Indeed, proponents of a path dependence perspective often celebrate historical accidents to explain the emergence of novelty. They relegate human agency to "choosing to go with a flow of events" that actors have little power to influence in real time. [14]

Garud and Karnøe promote path creation as an alternative view, conceptualising agency as "being distributed and emergent through the interactions of actors and artefacts that constitute action nets" [15]. Actors mobilize the past not necessarily to repeat or avoid what happened, but, instead, to generate new options. Likewise, people imagine new initiatives for the future which then lead them to mobilize the past in support. These retrospective and prospective memories are not the accomplishments of individuals acting on their own, but instead, memories that emerge through discussions and dialogue with others in real time [2, p. 770].

Agency is seen as an emergent, uncertain, relational and temporal process enabling many possible outcomes [16]. Path creation introduces elements of "aspirations for the future," "sensemaking of the past" and "conceptualisations of what is transpiring in the present" as interrelated tools for understanding agency. Organisational memories become both a foundation generating new options and potential allies for the development of new initiatives.

\subsection{Model}

Czarniawska [17] warns us about the obsession that social science has with labels, and how this obsession prevents one from answering the question "How does it work?" All too often this leads to ambiguous correlations which in turn can be misinterpreted as causality. The path dependent cluster literature includes many examples where companies labelled as part of a "cluster" are given a priori the property of increased competitiveness. They also show that a cluster per definition enables the diffusion of knowledge in a region. One forgets, however, to ask how it works or whether it works at all.

Czarniawska [17] introduces the action net model, shifting the focus from labels to actions, structures to processes and in our context from cluster to clustering. Action nets overturn the rationality and understand actions as the source of actors, making actors and organisations products rather than inputs. 
Paper-Clustering Ambiguities: How Companies and Public Bodies Develop a Cluster

\section{Method}

This study employs the action net model to clarify thinking and arguments as described in interviews with 12 representatives of participating companies, public bodies and organisations. The same theoretical framework is introduced for all actors, with no a priori assumptions, guided by proven concepts [16] such as radical indeterminacy [18, p. 181] and generalised symmetry [19, p. 200]. The interviews took place over a period of three months during the autumn of 2015. Researchers interview the informants in person for about 60-90 minutes. A semi-structured interview format is used, whereby clustering engagement topics are used as opening questions and the conversation is allowed to flow from there. All data used in the analysis are based on anonymised researchers notes alone. This approach is in line with the perspective taken and guides our research towards action not the individual person or role. The goal is to focus on clustering and how clustering affects an organisation.

All actions identified in the data are categorised and set up in a relational database using Gephi ${ }^{1}$. Actions identified in the analysis are used as edges and actors recognised by the actions are used as nodes in the relational database. Together they create a relational network based on actions identified in the interviews.

\section{$3 \quad$ Results}

\subsection{Analysis}

\section{The cluster project facilitating organisation}

The manager is new in this position. She/He is however familiar with the cluster project as she/he has long been a board member for one of the participating companies. She/He draws therefore on company/cluster engagement from the point of view, both of the company and the facilitating organisation, thus identifying actions originating from both perspectives.

Initially, she/he describes the cluster as an instrument for accessing public funding bodies with regard to financing and legitimising company R\&D. The R\&D projects are linked to disruptive technologies and the challenging of existing business models within the companies. She/He portrays the facilitating organisation as a passage point successfully harmonising funding bodies and private companies' programmes within the cluster project.

She/He also develops the idea of the cluster project as an opinion leader, setting the agenda for regional development funded and supported by public bodies, and mediating interactions between the funding bodies and the private companies.

Technology company \#1

${ }^{1}$ https://gephi.org/ 
Paper-Clustering Ambiguities: How Companies and Public Bodies Develop a Cluster

It is a small but expanding company describing itself as a pioneer in the industry. The company representative identifies several actions that describe the company's cluster engagement in the interview. She/He describes how the company is a product of an $\mathrm{R} \& \mathrm{D}$ project within the cluster project, and the ways in which they are cultivating and implementing key knowledge and technologies both from that and later R\&D projects, focusing on means of generating business opportunities. "Others are not interested in the business ideas. ... Disruptive innovation is central. ... Ask yourself the question where do we go next?"

She/He identifies developing relationships, ideas and research that are of value to one's own business as the rationale for engagement in the cluster project. The manager portrays internationalisation as another key element in the cluster project and its own knowledge transfer models. "We must get out and compete on the global arena. ... There are three reasons for international collaboration: Access to sales organisations, technology and business models.". Collaborating worldwide across regional boundaries is essential in the company cluster model. This collaboration is not only limited to trade, but includes technologies and the acquisition of knowledge. Cluster engagement is thus not understood as being confined by geographical proximity. Finally, she/he explains how new technology gradually becomes the core of the cluster project and how she/he works towards harmonising company and cluster activities, making this new technology the key selling point in both arenas.

\section{Technology group \#1}

The company manages infrastructure, services and sales in several locations in Norway. The manager identifies how the company business model open doors for engagement in the cluster project. She/He describes building close business relations. "Exciting expertise, technology and business models in the cluster. ... We are an active part of the research project. ... It is about new services". In the interview the manager describes the company as an active partner within the cluster. She/He describes linking its internal $R \& D$ to a cluster R\&D project, positioning a dedicated person from their own R\&D activities in the cluster project and thus accessing knowledge from the cluster centre of competence.

She/He recognises the difficulties regarding the dissemination of knowledge both within his own company and in a cluster, emphasising clustering as a relational process framed within technological materiality as an R\&D project.

\section{Public body \#4}

They describe themselves as a regional developer stimulating the labour market by encouraging regional innovation. They espouse such measures as the funding of R\&D, supporting business and industry networks and backing entrepreneurship, but when describing its own engagement, however, the actions are more limited.

The representatives describe how they are financing activities within the cluster project. A representative from the organisation is also permanent member (with observer status) on the cluster project board, legitimising, but as it is discussed, not influencing, the activities and strategies decided. They show little attention to the void between the 
Paper-Clustering Ambiguities: How Companies and Public Bodies Develop a Cluster

espoused ambitions, as a regional developer, setting the agenda, and its actual role in the cluster project.

\section{Public body \#2}

The regional representative from the public body financing $R \& D$ in the region identifies two governing actions in the public body's own cluster engagement in the interview: financing and legitimising. The representative describes how the body is financing the cluster project, as it has been doing for several years. First as part of a national business network programme and later as part of the ongoing cluster program. She/He informs us that she/he is a permanent member (with observer status) on the cluster board, legitimising, but not influencing the strategies and actions taken.

The representative also identifies a challenge within the cluster. She/He says "It is too constricted; it is about one company. It is not a partnership; it is more like a company." He explains that representatives of one of the technology companies is actively coordinating cluster activities.

\section{Public body \#1}

It is a major public instrument supporting innovation and development in companies and industries. The representatives especially identify the same actions described by the two other public bodies in their own engagement in the cluster project; financing and legitimising. They describe how it is financing the project and has been doing so for several years. First as part of a network program and later as part of a cluster program in a partnership with other funding. In the interview, they confirm that they are permanent members (with observer status) on the cluster board; legitimising but not influencing the strategies and actions taken.

The representatives expand the discussions on the blurred and unstable division of roles between the different public bodies. They are also aware of the limited number of active companies in the cluster project. The representatives see this as a weakness challenging the cluster project, but at the same time they give the cluster project credit for the results produced.

\section{Technology company \#3}

It is a result of the fusion of two companies and as a business model, in a state of change, moving towards service innovation. It is known internationally for technological solutions and services relating to infrastructure and management of infrastructure. The company became interested in the cluster project because of the reorientation towards new technology. The manager describes the company's cluster engagement as motivated by what we interpret as researching into and experimenting with disruptive technologies, together with other stakeholders within the cluster.

She/He describes success in finding partners and to some degree in accessing a knowledge arena with regard to public funding applications. She/He says, however, that they fail in many ways to employ this as an integrated part of their own innovation processes. One example is the challenges to property rights and patenting in interna- 
tional projects. They recognise their own inaction in relation to the cluster project facilitating organisation and in the cluster R\&D project in which they are participants. They later decided to leave the cluster.

\section{Technology company \#2}

It is known for technological solutions and services relating to infrastructure and infrastructure management, very similar to another company in the cluster. Its technology is thematic within the core of the cluster project but also competes with R\&D projects and other companies within the cluster. The manager tells a somewhat different story from other actors in the cluster project, discussing several actions concerning their own cluster engagement in the interview. She/He expresses the feeling that her/his company is out of synch with the cluster project. She/He describes how they experience the focus within the cluster facilitating organisation as being on the initiation of new projects. This is not in line with her/his own understanding of the cluster's purpose. She/He continues to explain how the company has the relevant competence and products and how they wish to meet stakeholders in what is a new and promising market. They are interested in experimentation, using the cluster for networking, and experimenting within disruptive technologies.

Using the company's experience in one of the R\&D projects as an example, she/he reveals what we understand as a gap between different mindsets within the cluster. She/He recounts how the introduction of their own technology failed to be taken seriously within the cluster project, who decided to develop a competing platform in a new company which was initiated from within the cluster R\&D project. Her/His illustration experiences what we interpret as an ambiguity in the cluster project, where the companies are supposed to collaborate and compete at the same time. This ambiguity proves to be difficult and challenging. They decided later to leave the cluster. She/He concludes as we understood him that the cluster is not a partnership that collaborate using existing competences. We interpret his arguments to "creating a cluster while building someone else's company??" to use a slightly altered expression from Feldman, Francis, $\&$ Bercovitz [20].

\section{Public body \#3}

It exists with the intention of contributing to the solving of regional challenges to the sponsoring of knowledge creation, enabling private and public organisations to increase competitiveness and productivity. The goal is to create growth and opportunities through company driven R\&D. They describe their own organisation as " $a$ pot of money" for financing research-based innovation such as a cluster project initiative. They claim to have an elusive partnership with other public bodies but see their own role as important for taking a regional perspective. "We know the regional challenges" as a quote shown in the research notes.

Their ambiguous relationship with the cluster project is clarified thus: While they are financing the cluster project, they also describe what we understand as a challenging history. This concerns finding ways to understand the role of the public bodies and to establish the nature of the relationship between organisations in the cluster. They express what we understand as an ambition to have closer collaboration with the cluster 
project and to make a greater contribution to the actual cluster roadmap. They acknowledge the challenges to achieving this, but they are still convinced that the cluster project would benefit from the more active and direct involvement of the relevant public bodies.

\subsection{Findings summary}

When the actions identified (and categorised) in the different interviews are drawn together into one figure, an action net is produced that identifies ways in which public bodies and private companies describe their own engagement, both within the cluster project (Fig. 1.) and in their relationships to one another.

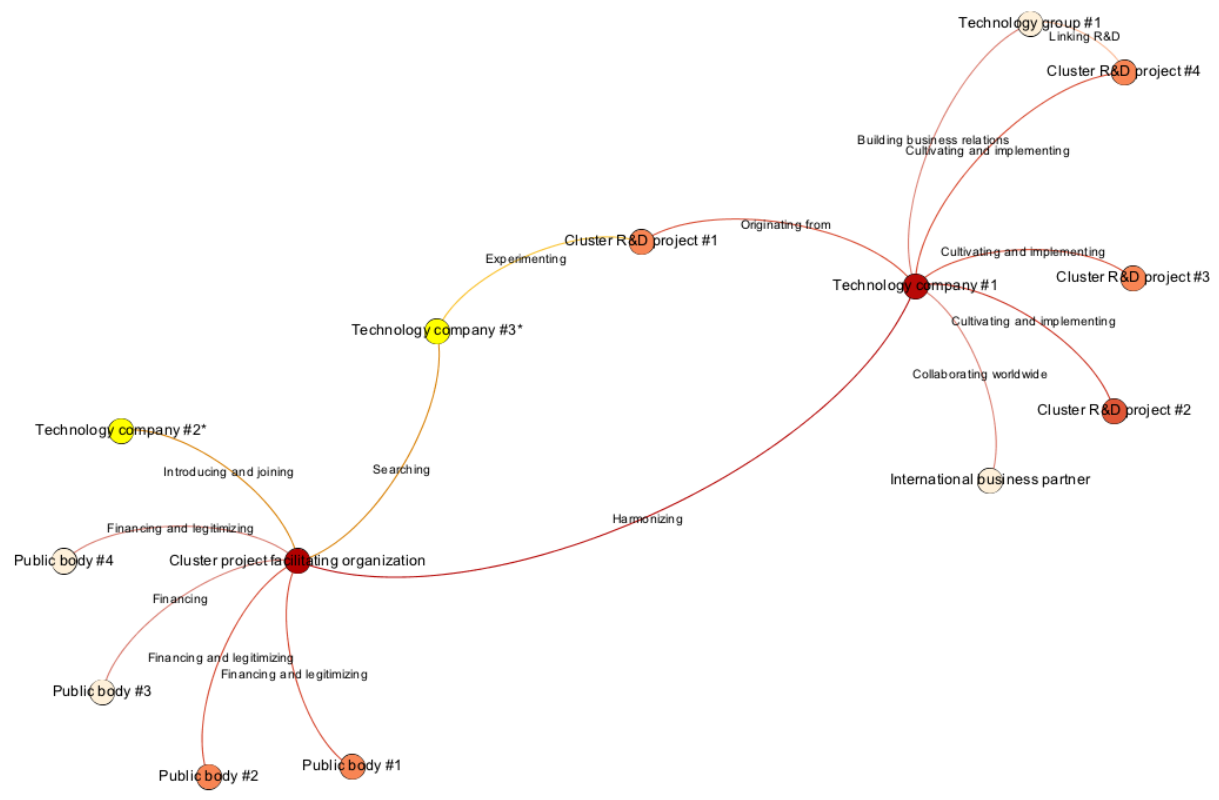

Fig. 1. Clustering action net and produced actors

The choice of colour specifies the connectedness of the node. Yellow nodes indicate actors leaving the cluster project. The clustering action net in Fig. 1. identifies two densely connected communities within the network: one made up of public bodies and the cluster project facilitating organisation and one made up of selected private companies and R\&D projects. A small group of actors harmonise transactions between the two communities. Different ways of relating to, engaging in and understanding the cluster project illustrate the decoupling of the cluster. 
Paper-Clustering Ambiguities: How Companies and Public Bodies Develop a Cluster

\section{Discussions}

In interpreting the data, we acknowledge the subjectivity of any interpretation. We do not wish to pretend that these are concrete findings that unambiguously support or disprove one hypothesis, as to do so would be to misrepresent the data and nature of the design used in this research. Research notes as data have several obvious restrictions but we will argue that they also make it possible to focus on and contribute to the understanding of clustering, especially in an early phase creating a ground for further research. We focus here on what we interpret as the most important actions and discuss their potential meaning and implications on clustering. We then use these elements to discuss items that we might need to be cognizant of in the further exploration of clustering.

In the introduction, the question was posed as to how companies and public bodies reflect and argue on their own engagement in a cluster project. Findings portray clustering as an array of different methods of relating to others within the cluster, different ways of engaging in a cluster and different ways of understanding clustering. In the interviews representatives from the companies and public bodies describe what we interpret as clustering ambiguities.

\subsection{Relating}

The clustering action net identifies two densely connected communities within the network: one made up of public bodies and the cluster project facilitating organisation and one made up of selected private companies and R\&D projects. Two companies are left in a void somewhere between the two communities. Both companies in question later decided to leave the cluster project.

The clustering action net in Fig. 1. illustrates how these communities are almost completely decoupled, only held together by a small group of individuals mediating transactions and harmonising activities between the two communities. This arrangement is often referred to as an obligatory passage point (OPP) [19] where one actor is in a position to align other actors' interests. We recognise the power of such a position. One example illuminating these tensions is the decision made by the cluster project facilitating organisation to develop a specific technology in a new company, instead of implementing already existing technology within one of the participating companies. This was made possible because of the OPP arrangement.

\subsection{Engaging}

The decoupling of the cluster is also visible in two very different ways of engaging in the cluster project. The public bodies describe a bilateral relation to the cluster project facilitating organisation that is almost exclusively about financing and legitimising the cluster. They appear to be locked into a loop of financing and legitimising, where one action follows the other in a never-ending helix.

The community of private companies describes a totally different engagement. It is characterised by the way in which company business models are tailored to the cluster project (and vice versa) and the construction of an almost complete value chain built 
around R\&D projects financed by the cluster project. This dynamic community describes high adaptive capacity in exploiting business opportunities as they surface, while implementing results from the R\&D projects. This constellation also proves successful in regard to public financing and recognition, as discussed earlier, but challenges the difference between a cluster and traditional business value chains.

\subsection{Understanding}

The findings also indicate varying and competing understandings of clustering. These differences create tensions within organisations when the void between what they say and what they do becomes significant enough. One example of this is when a public body expresses the importance of collaborating with the regional stakeholders within the cluster, has ended up with their role becoming "a pot of money" with little influence on strategies and actions. Competing understandings of clustering also create tensions between organisations within the cluster. One example of this is when two companies who express their understanding of clustering as networking, experimenting and researching, leave the cluster because of conflicts with others who interpret clustering as the implementation of knowledge and the creation of business value chains.

Holmqvist [21], [22] addresses the matter of parallel dynamics within and between organisations, introducing exploration and exploitation as concepts that illuminate differences, as well as competing understandings of the concept of clustering. Rubach et al. [12] explore the way in which companies exploit the business opportunities offered in a cluster project. Using Holmqvist's model, they conclude that the challenges faced are enmeshed in missing actions and the failure to interweave the varying approaches to engagement. The study's findings develop this argument further, describing how both understandings may well coexist within the cluster. Without processes bridging the differences, however, challenges and potential conflicts continue to arise.

\subsection{Agency}

The findings challenge dependency as a mechanism and the public cluster programs and bodies' rationale as to how to support competitiveness within the regions. They illuminate the ambiguous interpretation of agency, notably in the way in which public bodies not only support cluster initiatives (path dependence) but in many ways, create the cluster (path creation). The best example of public path creation is the publicly funded R\&D project that produced a company exploiting business opportunities which surfaced within the same project.

Public bodies create cluster features but the results of the creation are not necessarily what they intended. The public body representatives who were interviewed shed light on their ambiguous relationship with the cluster project. They experience being reduced to "a pot of money" financing cluster project activities which are then taken over and run by others. They also express the ambition of collaborating more closely with companies within the project, arguing that the cluster project and region would benefit from these contributions. They are left, however, with the paradox of creating the very same actors who later obstruct the ambitions for and intentions of 
the cluster program. These reflections and arguments reveal clustering as a changeable, indeterminate, temporal and precarious process.

There lies a challenge in the fact that the cluster is not a static formation or landscape. It proves to be fluid and adaptive. It is continually reassembled by numerous contributions, both intentional and unintentional, as described earlier. In addition, its role becomes blurred as it is continually pushed and pulled between differing understandings and methods of engaging in and relating to the cluster. Companies, individuals, the cluster project facilitating organisation, R\&D projects and national cluster programs all contribute to the assembling and reassembling of the cluster project.

\subsection{Policy implications}

The authors would argue that an important policy lesson is to be found in the way in which the government supported innovation clusters programme provokes radical changes in the very fabric of the cluster. The setting up of a cluster project facilitating organisation, which is based on a specific design in the programme and which funds networking activities and R\&D projects, does not so much strengthen the development of the cluster as create a new ambiguous cluster reality. The programme as an agent of radical change is especially challenging when paired with a path dependent understanding of the cluster project. It is then neither fully aware of the agency of the programme itself nor the possible biases and conflicting roles of the various technologies and human actors.

This study exposes agency as an emergent, uncertain, relational and temporal process. Agency illuminates clustering and the way in which cluster involvement affects an organisation. Two possible challenges produced by agency are the decoupling of the cluster and the problematic role taken by public bodies.

It is important to note that this is a limited study and may be judged based solely on research data based on interviews in one cluster project conducted during the autumn of 2015. Further research is recommended into types of agency and how engagement in differing cluster projects unfolds.

\section{Acknowledgment}

This work was supported and funded by the Research Council of Norway and the Regional Research Funds in Norway.

\section{$6 \quad$ References}

[1] P. A. David, 'Path dependence, its critics and the quest for "historical economics"', in Evolution and path dependence in economic ideas: past and present, P. Garrouste and S. Ioannides, Eds. Cheltenham, UK ; Northampton, MA, USA: Edward Elgar, 2001, pp. 15-40. https://doi.org/10.1017/s1053837200007690

[2] R. Garud, A. Kumaraswamy, and P. Karnøe, 'Path Dependence or Path Creation?: Path Dependence or Path Creation?', J. Manag. Stud., vol. 47, no. 4, pp. 760-774, Jun. 2010. https://doi.org/10.1111/j.1467-6486.2009.00914.x 
Paper-Clustering Ambiguities: How Companies and Public Bodies Develop a Cluster

[3] R. E. Miles, G. Miles, and C. C. Snow, Collaborative entrepreneurship: how communities of networked firms use continuous innovation to create economic wealth. Stanford, Calif: Stanford Business Books, 2005. https://doi.org/10.1016/j.pursup.2007.06.001

[4] R. Garud and P. Karnøe, 'Path Creation as a Process of Mindfull Deviation', in Path dependence and creation, 1. issued in paperback., New York: Psychology Press, 2012.

[5] M. Trippl, M. Grillitsch, A. Isaksen, and T. Sinozic, 'Perspectives on Cluster Evolution: Critical Review and Future Research Issues', Eur. Plan. Stud., vol. 23, no. 10, pp. 20282044, Oct. 2015. https://doi.org/10.1080/09654313.2014.999450

[6] R. Martin and P. Sunley, 'Path dependence and regional economic evolution', J. Econ. Geogr., vol. 6, no. 4, pp. 395-437, Apr. 2006.

[7] G. Andersson, 'Rethinking Regional Innovation', Syst. Pract. Action Res., vol. 26, no. 1, pp. 99-110, Feb. 2013. https://doi.org/10.1007/s11213-012-9265-5

[8] S. Rubach, 'Company learning in a network: a dual organization-development (OD) process : bridging the learning processes in a network and the local learning processesin the participating company', Norges teknisk-naturvitenskapelige universitet, Trondheim, 2011.

[9] P. Karnøe and R. Garud, 'Path Creation: Co-creation of Heterogeneous Resources in the Emergence of the Danish Wind Turbine Cluster', Eur. Plan. Stud., vol. 20, no. 5, pp. 733752, May 2012. https://doi.org/10.1080/09654313.2012.667923

[10] A. Kleiner and G. Roth, 'How to make experience your company's best teacher', Harv. Bus. Rev., vol. 75, no. 5, pp. 172-177, Oct. 1997.

[11] G. Andersson, 'Resisting Organizational Change', Int. J. Adv. Corp. Learn. IJAC, vol. 8, no. 1, p. 48, Mar. 2015. https://doi.org/10.3991/ijac.v8i1.4432

[12] S. Rubach, F. R. Johansen, and G. Andersson, 'Missing Actions in Cluster Innovation', Int. J. Adv. Corp. Learn., vol. 7, no. 1, pp. 17-23, 2014. https://doi.org/10.3991/ijac.v7i1.3524

[13] R. Garud, R. L. M. Dunbar, and C. A. Bartel, 'Dealing with Unusual Experiences: A Narrative Perspective on Organizational Learning', Organ. Sci., vol. 22, no. 3, pp. 587-601, Jun. 2011.

[14] R. Garud and P. Karnoe, Path Dependence and Creation (2001). Psychology Press, 2001.

[15] R. Garud, A. Kumaraswamy, and P. Karnøe, 'Path Dependence or Path Creation?', J. Manag. Stud., vol. 47, no. 4, pp. 760-774, Jun. 2010. https://doi.org/10.1111/j.14676486.2009.00914.x

[16] M. Michael, Actor network theory: trials, trails and translations, 1st edition. Thousand Oaks, CA: SAGE Ltd, 2016.

[17] B. Czarniawska, A Theory of Organizing: Second edition. Edward Elgar Publishing, 2014.

[18] M. Callon, 'Actor-Network Theory - The Market Test', in Actor Network Theory and After, J. Law and J. Hassard, Eds. Blackwell Publishers, 1999.

[19] M. Callon, 'Some elements of a sociology of translation domestication of the scallops and the fishermen of St Brieux Bay', in Power, Action and Belief. A new Sociology of Knowledge?, J. Law, Ed. London: Routledge \& Kegan Paul, 1986, pp. 196-233. https://doi.org/10.1111/j.1467-954x.1984.tb00113.x

[20] M. Feldman, J. Francis, and J. Bercovitz, 'Creating a Cluster While Building a Firm: Entrepreneurs and the Formation of Industrial Clusters', Reg. Stud., vol. 39, no. 1, pp. 129-141, Feb. 2005. https://doi.org/10.1080/0034340052000320888

[21] M. Holmqvist, 'A Dynamic Model of Intra-and Interorganizational Learning', Organ. Stud., vol. 24, no. 1, pp. 95-123, Jan. 2003.

[22] M. Holmqvist, 'Experiential Learning Processes of Exploitation and Exploration within and between Organizations: An Empirical Study of Product Development', Organ. Sci., vol. 15, no. 1, pp. 70-81, 2004. https://doi.org/10.1287/orsc.1030.0056

Article submitted 2018-10-21. Resubmitted 2018-12-22. Final acceptance 2019-01-15. Final version published as submitted by the authors. 